\title{
Erratum to: Communications and Multimedia Security
}

\author{
Bart De Decker ${ }^{1}$, Jorn Lapon $^{2}$, Vincent Naessens ${ }^{2}$, and Andreas Uhl ${ }^{3}$ \\ 1 K.U. Leuven, Department of Computer Science - DistriNet, Celestijnenlaan 200A, \\ 3001 Leuven, Belgium \\ BartDe.Decker@cs.kuleuven. be \\ 2 KAHO Sint-Lieven - MSEC, Gebroeders De Smetstraat 1, 9000 Gent, Belgium \\ \{Jorn. Lapon, Vincent. Naessens\}@kahosl . be \\ 3 University of Salzburg, Visual Computing and Multimedia, Jakob Haringer Str.2, \\ A 5020 Salzburg, Austria \\ uhl@cosy.sbg.ac.at
}

\section{Erratum to: \\ B. de Decker et al. (Eds.) \\ Communications and Multimedia Security \\ DOI: $10.1007 / 978-3-642-24712-5$}

The book was inadvertently published with an incorrect name of the copyright holder. The name of the copyright holder for this book is: (c) IFIP International Federation for Information Processing. The book has been updated with the changes.

The updated original online version for this book can be found at DOI: $10.1007 / 978-3-642-24712-5$

B. de Decker et al. (Eds.): CMS 2011, LNCS 7025, p. E1, 2011.

(C) IFIP International Federation for Information Processing 2017 